a large portion of small intestine (jejunum and ileum) was found to be black and gangrenous, with some slight recent adhesions of the affected coils; there were great vedema and swelling of the mesentery. It was found on examination that the portion of the small intestine supplied by the intestinal branches of the superior mesenteric artery was almost entirely gangrenous, while the nutrition of the bowel supplied by the other branches of the same artery was more or less impaired. A careful search was made for thrombi; most of the intestinal veins of the affected area contained dark clots, while I think I found a thrombus in one at least of the small mesenteric arteries. I found no thrombus in the superior mesenteric vessel itself, but when I dissected it to its origin I found that the first part of the artery and a considerable portion of the abdominal aorta immediately surrounding the origin of the superior mesenteric artery were in a state of advanced atheroma (calcareous). The lumen of the superior mesenteric artery was very much diminished by this condition. Thrombi were found in the right brachial artery completely filling the lumen of the ressel. The heart was flabby; the aorta was slightly atheromatous. The innominate artery washealthy and also the thrombosed brachial. I have omitted all the other details of the necropsy as the description of the case will indicate them, I hope, sufficiently clearly.

Thrombosis is, I believe, a fairly frequent sequela of influenza. I have before me a newspaper cutting relating the death of Dr. Henrici, Surgeon-General of the Fifth German Army Corps. He had one of his legs amputated for gangrene from thrombosis following influenza and died shortly afterwards. In Dr. Lockie's case the abdominal symptoms were very obscure till the thrombosis in the brachial artery occurred. After this it was thought probable that some thrombotic mischief was at work in the abdomen, but the exact nature of it was of course impossible to decide. It is rare that a pathological condition exists so favourable for thrombosis as in this case of partial obliteration of a large artery and I think the case is sufficiently interesting to warrant my placing the facts before the profession.

Temple Sowerby, Penrith.

\section{ON PARACENTESIS OF THE CHEST IN CASES OF PULSATING PLEURISY AND PNEUMOTHORAX.}

BY ERNEST POWELL WATKINS, L.R C.P. EDIN. \&c., IATE CLINICAL ASSISTANT IN THE ROYAL AND WESTERN INFIRMARIES, GLASGOW.

AMongst the many complications of pulmonary phthisis none gives the surgeon greater anxiety than pneumothorax, the mortality of which, according to Dr. West's statistics, is 66 per cent. ${ }^{1}$ It occurs most frequently on the left side of the chest, ${ }^{2}$ and as regards sex it is more common but less fatal in men than women, and phthisis accounts for no less than 90 per cent. of all cases. ${ }^{3}$ Pulsating pleurisy is such a peculiar concomitant that the following case, rare as it is, is without doubt worth recording.

E. $\mathrm{T} \longrightarrow$, aged eighteen, warehouse girl, was seen on May 2nd, 1890, complaining of pains, lancinating in character and referred to the left infra-mammary region. The patient, an intelligent girl of neurotic temperament and somewhat emotional, stated colloquially that the pains were intensified not only when she coughed or breathed but upon palpation or the slightest exertion. Four days previously to obtaining advice she believed she strained herself by lifting a box on to a shelf, when the latter gave way, so that she had to use all her strength to prevent its falling on a belpmate who came to her rescue. From that moment she had a pain in the side and back, which, she states, was preceded by a sharp and short stab and a sensation of something having given way. She was able, with considerable difficulty, to attend business for some hours after the accident, but towards evening became so ill that she was taken home, where for four days she was continually poulticed and purged by her relatives, who, on the evening of the fourth day,

1 THE LANCE', vol, i. 1884, p. 792.

2 Vincent D. Harris: Diseases of the Chest, p. 166.

3 Powell: Diseases of the Lungs, p. 131 . finding that she was getting worse, thought it wise to obtain medical advice.

Personal history. - The patient states that she has been "out of sorts" for the past seven years-i e., since 1884-from which time she has been under medical treatment on and off for what, in the patient's phraseology, is a short, dry and hacking cough, bad digestion and habitually moist bands. In 1887 an attack of scarlet fever was superimposed on this, the fever being accompanied with ear mischief, abscess in the neck and subsequent partial deafness. From sixteen years old her health improved and she commenced to menstruate, the catamenia being normal in relation to colour, quantity, duration and regularity; but on her seventeenth birthday menstruation suddenly ceased, the patient attributing this to a severe chill, after which the old symptoms enumerated above reasserted themselves.

Family history. - Father and mother, aged respectively sixty and fifty-one, are in good health. She has two brothers, one a robust lad of sixteen, the other a strumous boy aged eleven. One brother died aged twenty-two from phthisis.

Physical examination.-May 6th (four days after the accident): Patient not badly nourished, but pale with flushed cheeks, hurried breathing and decided expression of pain. Chest is somewhat narrow with wide interspaces, angle of Ludovici being abnormally prominent, a bruise on the mamma and a small lacerated wound, healing by suppuration, in the interval between the pectoralis major and left deltoid. The supra-clavicular fossa is deeper on the right side, below which a certain degree of flattening is also noticed. There is an old cicatrix in the neck, probably the site of a scarlet fever abscess; skin dry, hot and harsh. The tongue is two-thirds posteriorly coated with brownish fur. Bowels constipated; appetite in abeyance. Urine scanty, high coloured, transparent; sp. gr. 1020, acid, loaded with urates; no albumen, sugar or bile; chlorides almost negative. Temperature $1012^{\circ}$; pulse 100 ; respiration 20. Pain is referred entirely to the left side, from below the scapula to the nipple. Tactile fremitus marked. No appreciable difference in the percussion note as compared with the other side. Pleuritic rub is distinct over the left side, non-synchronous with the heart, and abolished when patient holds her breath. Exaggerated breathing is vesicular in character over the unaffected side, as high as the second interspace, above which breathing is of bronchial quality. Cardiac sounds very plain over this region.

May 7th: No change in the condition of the patient.8th: Opposed pleural surfaces separated, as evidenced by dulness over the left pleura, entire absence of friction; vocal resonance and vocal fremitus are abolished. Heart displaced to right side; sounds most distinct in mid-sternal line. No increase of measurement of the left side; the interspaces plainly marked. Temperature $101^{\circ}$; respiration 20 ; pulse 100 . 9 th and 10th: The objective and subjective symptoms are the same.-11th : Fluid is accumulating rapidly. The intercostal sulci are abolished. The girth of left side is increased one inch and a haif ; marked increased resistance on percussion ; Skoda's resonance below the left clavicle; respiratory space crippled and dyspnoa noticed for the first time; cardiac impulse to-day in para-sternal line in the third right interspace. Pain intense on palpation. Temperature $102^{\circ}$; pulse 100 ; respiration 20. 12th, 13th, 14th: No change in the symptoms.-15th: Fxpansion and interspaces indistinguishable. - 16th and 17th: Dulness extends from the lower border of the infra-clavicular region of the left side to the right border of the sternum, the percussion note being clear for three-quarters of an inch only below the left collar bone. Superficial veins of the chest are engorged. Cardiac displacement more marked. Epigastric pulsation and orthopncea are present. Respiration is shallow. Cough and blood-stained sputum are probably caused by the excessively hyperæmic condition of the sound lung, which may be an important factor also in the causation of the extreme dyspacea. It was evident therefore that the patient was trying her utmost to draw on the lungs for supply and had, in fact, lived up to her respiratory limits, and was fast becoming bankrupt for breath ; a hypodermic syringe was introduced, when a few drops of clear fluid came away. After this the patient was placed on her back, inclining to the affected side, the skin was forcibly drawn orer the rib so that the puncture might not correspond with the pleura, but form a valvular orifice, the thorax beingaspirated in the fifth interspace at a spot where the respiratory murmur was absolutely inaudible, and when $36 \mathrm{oz}$. of fluid were withdrawn epigastric syncope occurred, the needle was withdrawn, and 1 oz. of pale brandy administered.18th : Feels relieved. Respiratory murmur audible as far as 
the fourth interspace; heart in mid-sternal line; no epigastric pulsation. Temperature $99^{\circ}$; respiration 18 ; pulse $80 .-$ 19th : Patient is improving; it was hoped that the withdrawal of the greater quantity of fluid would tend to complete absorption by relieving the overstrained lymphatics - 20th : The symptoms are the same as yesterday. 21st: Fluid had reaccumulated and cardiac impulse was again seen in para-sternal line, and the symptoms were those of the 17th inst., save that the temperature to-day was $103^{\circ}$, respiration 28 , pulse 100 . She had a severe rigor in the night and has been sweating this morning, the sweating being colliquative in character. An ægophonic sound is heard at the angle of the left scapula; this sound may be more correctly described as being markedly nasal and continuous, instead of bleating, depending probably upon the interception (by exudation) of the fundamental vowel tone and the passage of harmonic overtones. - 22nd : Cardiac asthenia present. Paracentesis thoracis resorted to and $\$ 0 \mathrm{oz}$. of fluid (turbid) slowly withdrawn, after which the patient improved until the 25 th inst., when the following notes were taken : "Improved on the whole, but still complains of pain in the left side, which is now quite immovable. Temperature $101^{\circ}$; pulse 80 ; respiration 20 . Percussion note dull below the third rib; tactile fremitus obtained only above its apper border. Below these points breathing is distinctly amphoric. Heart still displaced."-26th : Left side seems much more enlarged and rounded than hitherto and movements are absent. Bell sound is plainly elicited. Dulness extending from the lower border of the third rib is distinctly movable; this is seen if she turns on her back or right side, the percussion note in the axilla being hyper-resonant. - 27th : To-day, from the third to the sixth interspace in the mid-axillary line, a distinct pulsation or heaving is noticed, the thoracic parietes receiving a marked impulse, synchronous with the ictus cordis, and also systolic in time with the cardiac impulse, which is now defined in the fourth right interspace external to the junction of the cartilages with the sternum. The hand when placed on the side is forcibly lifted at each pulsation. - 28th: Patient lies in the left lateral decubitus, and in this position the impulse of the heart can be felt in the fourth right space, the pulsations in the left mammary region being plainer to-day. Bell sound.s very distinct. Succussion absent. -29th : Signs similar. Systolic impulse on the left side can be seen at the other end of the room, ten feet away. Resonant note is obtained to the upper border of the third rib ; from the third to the fifth it is tympanitic and below this point dull. Temperature $101^{\circ}$; pulse 80 ; respiration 20 . Distinct amphoric breathing under the axilla. A needle was introduced and a few drops of pus withdrawn, after which ten ounces of pus were removed from below the inferior angle of the left scapula and a drainage-tube inserted - 30th, 31st: The patient is improving. Temperature $99^{\circ}$. - June 1st, 2nd: Flattening has taken place in the interspaces and the note is tympanitic from the fourth to the seventh. The patient expresses herself as feeling better than she has all along. - 4th : The discharge is very slight; tube removed; a No. 2 (catheter size) introduced. Temperature, pulse and respiration normal. Normal breath sounds over the right lung. - 7th : There being no discharge, the drainage-tube was withdrawn. - 30th : Sinus has healed. Relatives state that the patient looks better than she did before the accident occurred. The chest is still much flattened, the heart now beats to the left of the sternum, but the impulse and first sound are felt and heard in a line one and a quarter inches to the right of the left nipple.

The patient was seen in a month after I discharged her. The notes made were that " although there was considerable flattening of the left parietes there were lond and breezy sounds heard down to the fourth interspace; below this they were somewhat feeble.

Remarks...-The special features in this case are the patient's descriptive account of her sensation of something having given way, the remarkably rapid and copious effusion and the intense agony on palpation or even application of stethoscope. From these special features I am led to beliere that it was a pneumothorax from the first and that it is one of those interesting cases recorded in the Clinical Society's Transactions by Drs. West, De Havilland Hall and Osler. A pneumothorax cannot always be diagnosed at first ; for it is well known that the percussion note may be dull when the tension of the thoracic wall is too great, such as it may have been in this case, and, on the other hand, there must be a certain degree of tension in the walls of the carity to make them good reflecting surfaces, and if this tension be deficient at the spot of the carity oppozite the place where the stethoscope is applied the tinkling sounds may be absorbed and not reflected. Careful studies of pulsating pleurisies were first recorded in 1844 by Dr. Macdonnell, ${ }^{4}$ Professor of Clinical Medicine in McGill University, Montreal, who at that time was clinical assistant to the renowned Graves and Stokes of the Meath Hospital. Coomby states that of thirteen cases nine died, ${ }^{\mathbf{5}}$ and in Kepler's practice out of thirty-eight cases seventeen died. ${ }^{6}$ Two groups of cases are recognised-viz., the intra-pleural and empyema, in which there is an external pulsating tumour. The latter usually occurs in cases in which the fluid has existed for some time; but that it does occur in acute cases, even with serous exudation, is verified in the cases reported by Dr. Osler of Pennsylvania. ${ }^{7}$ Various suggestions for the phenomenon are put forward, one being that it occurs when adhesions exist between the layers of the pericardium and between the latter and the chest wall $;^{8}$ but in the report of some post-mortem examinations such adhesions were not found. Bouveret, in his recent monograph, holds that pulsation is met with whenever the resistance of the thoracic wall is greatly reduced, and Traube inclines to this belief. The indications for treatment seem to be, as in this case, complete evacuation and permanent drainage.

CASE 2-W. H. P-, aged twenty-six, clerk, who has been treated for pulmonary phthisis and whose family history is bad, sent an urgent message to me on May 18th, stating that "he had wrenched his inside" by assisting a drayman to " trestle a cask." He was in a prostrate condition when I arrived, vomiting and sweating profusely. Temperature $1044^{\circ}$; pulse 130 , thready. The pains in this instance were referred to the left side, which was fixed. A highly resonant note was obtainable over the front and side. Vocal resonance and vocal fremitus were absent. A sixth of a grain of morphia was given hypodermically and repeated in three hours, and the patient was enjoined to swallow a couple of teaspoonfuls of pale brandy in a little water. I resorted to fixation of the side by means of strapping, and this relieved the patient in no little degree.-May 19th: Patient expectorated some blood-stained and mucoid sputum. Temperature $103^{\circ}$; pulse 130 . Patient too ill and pain too great to localise the position of the heart. $-20 \mathrm{th}$ : Signs of great intra-thoracic pressure evident. Pulse very small, feeble, and rapid. Patient insists upon being allowed to stand or sit upright. Evening temperature $104^{\circ}$; pulse 140; left side distending; bell sounds well marked. The chest was punctured. A modification of Dieulafoy's aspirator was used; the contained air in the receiving bottle having been thoroughly exhausted, a quantity of gas was drawn off with about one ounce of fluid slightly streaked with blood. The heart moved to its original position. -21st : Patient improved; temperature $101^{\circ}$; pulse 120 ; respiration 28 . Patient was not disturbed to examine the chest.-22nd: Expansion again evident; amphoric breathing with tinkling râles, and fluid has formed in the left pleura. Temperature $101^{\circ}$; pulse 120 . There being no cyanosis or cardiac asthenia, tapping was deferred.-23rd, 24th, 25th: Symptoms and physical signs are the same as those of the 22nd. $-26 \mathrm{th}$ : Symptoms became urgent and paracentesis was resorted to. A quantity of air came away and twelve ounces of fluid. From this date he improved, and in five weeks he was able to attend the surgery, when examination showed that the breath sounds, although weak, could be distinctly heard back and front. After this the patient went south and I saw no more of him.

Remarks. - When a pneumothorax terminates in recorery the aperture in the lung must have healed and the gases been absorbed. As this takes place the pulmonary tissue is reinflated simultaneously, but recovery, at any rate partial, takes place most often in those cases which are circumscribed. The treatment of pneumothorax by aspiration is not advised by the leading authorities. Professor Gairdner advocates puncture. ${ }^{9}$ Dr. Clifford Beale thinks it is unadvisable to meddle with the chest unless the danger to life is immediate. ${ }^{10}$ Dr. Douglas Powell advocates the introduction of the trocar when there are signs of pressure within the thorax, ${ }^{11}$ but Dr. Wilson Fox believes that it causes secondary effusion. ${ }^{12}$ If the use of the trocar be accepted as the final treatment of the cardiac asthenia of

4 Dublin Journal of the Medical Sciences, 1844. 5 Archives Générales, 1883

$\tau$ International Journal of the Medical Sciences, November, 1883.

8 Broadbent: THE LANCET, May 24 th and 31st, 1884 9 THE LANCET, July 2nd, 1892

10 Kingston Fowler : Dictionary of Medicine. p. 661.

Powell : Diseases of the Lungs, p. 142 .
12 Fux : Diseases of the Pleura, p. 1118. 
roneumothorax we cannot expect relief in cases in which the increasing pressure within the chest is not greater than that of the atmosphere. This statement is also borne out in the reports of Dr. Sutherland of the North London Hospital for Consumption. Where tuberculous matter becomes deposited on the parietal pleural surface agglutination may take place between it and the pulmonary surface, with the result that the adhesion between the visceral and the costal layers may save the tuberculous patient from a pneumothorax. This wis medicatrix nature is often exerted; and in a like manner a pneumothorax once formed may retard the phthisical process by giving lest to the diseased lung through compression. In such a case the therapeutical effect of the pneumothorax may be effective in benefiting the phthisical patient for a short period. It might be supposed that individuals whose lungs are greatly reduced by the subsequent contraction of the chest would necessarily be reduced to a frail state of health and low scale of bodily strength, yet, curiously enough, some persons wan follow the active pursuits of life, as instanced in Case 1. Iaennec mentions the case of a distinguished Paris surgeon who, although he had one side contracted in a marked degree from empyema, yet enjoyed the best of health and lectured to his students twice daily. A similar case came under my observation in Bedfordshire, the subject of which is now getting his living as a flautist.

Shakespeare-villas, Nottingham.

ב-

\section{REPORT ON}

\section{AN OUTBREAK OF ENTERIC FEVER IN}

\section{WARDS 3,4 AND 5 OF THE BOROUGH OF LEICESTER.}

BY J. PRIESTLEY, B.A. LOND., M.D. EdIN., D.P.H. CAMB., MEDICAL OFETCER OF HEALTH AND PUBLIC ANALYST, BOROVGH OF LEICESTER.

From January to April of last year there were two cases of enteric fever notified as having occurred in Wards 3 , 4 and 5 of the Borough of Leicester. Since then twenty cases have been reported-viz., three in May, four in June, five in July, five in August and three in September. All these I have succeeded in tracing directly or indirectly to the consumption of herb beer infected, in my opinion, with enteric fever contagium.

The first case was that of $\mathrm{F} . \mathrm{M}$ - in $\mathrm{B}$ - street, a five-roomed house. He was notified as suffering from enteric fever on May 7th, and on investigation it was found that he had been ill for eleven days. The child was lying on an improvised bed in a back room, where he had lain for that time, the front room being used as a shop, where provisions, herb beer \&c. were sold. The back room was in use as a living-room for the whole family, consisting of Mr. and Mrs. $\mathrm{M}$ - seven children and the grandfather. At the time of the inspector's visit Mrs. M — - was engaged in brewing the herb beer in the room where the child suffering from enteric fever was lying. A puncheon containing a few gallons of herb beer was standing in the room without a cover and in the act of being fermented with yeast. An iron pot containing boiling herbs was on the fire. The mother was cautioned by the inspector as to the danger she was incurring by brewing herb beer in a room in which a fever patient was lying, and the child was some days afterwards (May 20th) removed to the infirmary; but no further action was taken, as this was the time during which there was no medical officer of health in Leicester, my predecessor having died.

Since this case nineteen others suffering from enteric fever have been notified, and on making strict inquiries and close investigations as to drainage defects and milk and water supplies at the houses in which the cases occurred, I was satisfied that the facts that were brought out were not sufficient to account for all the cases, or even for the majority. I was accordingly led to look further, and a fact that attracted my attention was the "good trade" that was being done in the sale of herb beer from the very shop in the back room of which the child (F. M- had been found by the inspector to be suffering from enteric fever and where the herb beer was actually made. Starting from B- street as a centre I succeeded in tracing the herb beer definitely co nine and indefinitely to six of the houses where enteric fever had been notified as having occurred. In only five out of the twenty cases was I unable to get a history of herb beer having been drunk. I may explain that in using the word "definitely" I mean the history was distinct and the case proved conclusively-e.g., "gift" tickets given away to purchasers of the herb beer were shown \&c.; whereas in those cases I have described as "indefinitely" traced, mean that the evidence of herb beer drinking was distinct, but it could not be traced to $\mathrm{B}-$ street. Considering, however, that the houses were in the neighbourhood and that young people are apt to spend their pennies without being able to tell exactly a little while after where they spent them, we may reasonably suppose that some of the indefinite cases may also have partaken of the infected beer. Then, again, I was able to trace the fact that one other shop dealing in herb beer had on emergency replenished its supply temporarily from $\mathrm{B}$ - street, so that we may conclude that of the twenty cases fifteen had a history more or less definite of having partaken of the infected beer. I am by no means satisfied in my own mind that the remaining five cases had not also partaken of it, but from a statistical standpoint I am sorry I have been unable to prove this conclusively.

I may mention here that several cases of illness which the medical men in attendance have not felt justified in notifying as enteric fever, but which they have admitted were of a distinctly enteric type, have come to my knowledge. The important bearing of this must be erident when I say that I myself, as medical officer of health without private practice, have seen ten such cases lately.

An interesting though tragic episode in the epidemic deserves mention. On Aug: 8th Mrs. M- (the mother) who brewed the herb beer was notified as suffering from enteric fever. She had been ailing off and on for fourteen days previously, and on July 25th she, with her husband and family, removed to $\mathrm{M}$ - street, taking with them six bottles of herb beer which they had in stock from $\mathrm{B}$ street. Mrs. M- was finally removed to the infirmary on Aug. 12th and died there on the 27th. I have succeeded in tracing the six stock bottles that were taken from $\mathrm{B}-$ street to $\mathrm{M}$ - street, two of them having been sold to a Mrs. B w who at present is in good health, and the other four having been drunk by the M-_-'s themselves, of whom another has since been notified as suffering from enteric fever (Aug. 26th). Indeed, of the M- - family mentioned above the grandfather has alone escaped, while four have had enteric fever (one dying) and the remaining five have suffered more or less from pseudo-enteric symptomse.g., purging, low fever, depression \&c. The grandfather's escape is explicable by his age.

The ill-fated house in B- street was left by the $\mathrm{M}$ - - 's on July 25th and taken on the same day by a family named B-.., who have brewed and sold other herb beer since. 'There is no illness in the house now, and the M-s'stock has been removed, not a single bottle remaining in B- street

With a child lying ill of enteric fever in a room where the mother was brewing herb beer it is not very difficult to understand how the mother's hands may have conveyed the germs from the patient into the beer. I need not, I think, however, go so far as this. It is sufficient for my purpose to know that the herb beer when brewed stood uncovered for hours in a room in which a child was lying ill of enteric fever, with a chamber utensil (probably containing typhoid stools) on the ground.

The medical histories of the cases are very definite. Taking the first case in B-. street as the infecting centre, and remembering that the child was lying ill in the back room from about May 1st until the 20th-when he was remored to the infirmary-we can understand how the beer brewed during that period was contaminated.

Though the sewage of this particular area is not perfect, there is nothing specially calling for remark, whilst other areas of the town (where the sewerage is worse) show a clean bill as regards enteric fever. Then, again, all the houses affected do not drain into one separate system and the sanitary arrangements are all external. The sinks in all cases were disconnected from the main drainage. All the houses were supplied with the Corporation water, which at that time was good.

Inquiry into the milk-supply of the varions houses infected gave negative results, though it is a strange coincidence that one particular milkman supplied nine out of the $t$ wenty cases. Careful investigations in this direction, however. showed nothing amiss. I was thus driven to look elsewhere, and I 